\title{
La influencia de la época medieval sobre el judaísmo actual
}

The influence of medieval times upon actual judaism

Adrián Tolentino adtolentino@outlook.com Universidad Iberoamericana México

\section{Resumen}

La importancia del estadio medieval de la religión judía se ha pasado por alto al estudiar su evolución. Generalmente, el análisis de la configuración estructural de la religión se enfoca en los estadios ubicados en la Antigüedad, por ser precisamente un periodo vastamente prolífico al respecto. En esta investigación se pone de manifiesto la latencia que tiene el medioevo respecto de la estructura y función del judaísmo. Se ha recopilado una serie de elementos, dentro de múltiples ámbitos como lo son la escritura, las prácticas religiosas y la lengua, entre otros. Al repasar esta recolección de elementos se caerá en cuenta de la vigencia, totalmente inmutada, del judaísmo medieval sobre el actual.

Palabras clave: Medioevo - Maimónides - Ibn Paquda - Yehuda HaLevi - Elementos inmutados - Desarrollo religioso - Cábala. 


\begin{abstract}
The importance of the medieval stage in the Jewish religion has been passed over in the study of its evolution. Generally, the analysis of the religion's structural configuration is focused on the stages located on Antiquity, for it being precisely a vastly prolific stage in these regards. This investigation highlights the latency that the medieval times have gotten regarding Judaism's structure and function. We present a compilation of a series of elements, regarding multiple ambits like writings, religious practices, language, among others. When reviewing this selection of elements, there will be an awareness of the totally unchanged vitality of Medieval Judaism present in the actual one.
\end{abstract}

Keywords: Medieval times - Maimonides -Ibn Paquda - Yehuda HaLevi - Unchanged elements - Religious development - Kabbalah.

\title{
Introducción
}

En el presente trabajo se expondrá una tesis que demuestra la gran trascendencia que tuvo el medioevo en cuanto a las prácticas religiosas de los judíos de nuestra época, esencialmente observando las costumbres dentro de la personalidad colectiva judía que se desenvolvió en lo que hoy conocemos como Europa; si bien, hablar de la Edad Media siempre es complejo, aun cuando la delimitemos a un espacio geográfico como lo es Europa, puesto que se entiende como un período de casi diez siglos. Es precisamente por esta causa que el enfoque se hallará en el lapso de tiempo comprendido entre los siglos XI y XIV, que es el momento de mayor importancia en el judaísmo medieval (Küng, 1993) ${ }^{1}$. Es importante destacar que el desarrollo del judaísmo mediante el paradigma rabínicosinagogal (Küng, 1993) de la religión se consolida durante estos siglos, lo cual es, fuera de

\footnotetext{
${ }^{1} \mathrm{Su}$ estudio de la historia del judaísmo se divide en el modelo propuesto por Thomas S. Kuhn de los paradigmas. Así, el paradigma en cuestión es nombrado por él como el "paradigma rabínico -sinagogal”. Cfr. Küng, H. (1993). Das judentum, München. Zurich/Tubingen: Piper, p.7
} 
toda duda, de capital importancia. La personalidad religiosa que toma el judaísmo durante dicha época es producto de una identidad gestada en los últimos años de la Antigüedad y que se desenvolverá en su máxima expresión durante la Edad Media, que innegablemente son cuestiones básicas que aún en la actualidad observamos.

Es evidente que, como cualquier proceso histórico de toda sociedad, los estadios más próximos a la actualidad consolidan elementos que aún hoy podemos percibir. El judaísmo, por conformar una identidad cuasi homogénea a finales del mundo antiguo y por su tenencia de una génesis antiquísima, representa una sociedad asaz particular por su permanencia y su vigencia en nuestras sociedades. Especialmente, por su supervivencia a lo largo de los siglos en un carácter de comunidades segregadas distanciadas de su lugar de origen, esto es, la supervivencia en una diáspora.

Resulta productivo analizar cuáles elementos, que el judaísmo actual —independientemente de la rama, sea el judaísmo reformado, ortodoxo, o conservador; y las subsiguientes divisiones pertenecientes a cada corriente (liberales, haredim, jasídicos, masortís) — aún mantiene aquellos que fueron originados durante el medioevo, puesto que la diáspora, ya desde dicho momento, tenía una identidad sólida. Fuera de toda duda, partimos del supuesto factual que asevera que todo elemento en una sociedad es producto de la evolución de otro proto-elemento o pre-elemento, que concibió un origen en las etapas iniciales de dicha sociedad y, es por esto, que el actual trabajo implica ciertas dificultades.

Es apremiante esclarecer que cada uno de los elementos medievales del judaísmo evolucionaron en otros elementos en la modernidad y en épocas posteriores, por lo que el actual ensayo indagará por aquellas prácticas que se desarrollaron en el medioevo tardío y que aún se mantienen tal y como se desenvolvieron en dicho momento. Es decir, aquellos aspectos sociales, religiosos, filosóficos o culturales que en la actualidad conservan el cariz histórico medieval. Rasgos que no sufrieron modificaciones con la llegada de nuevas constelaciones globales de convicciones y recientes acaecimientos que pudieron modificar otros elementos hasta evolucionar en caracteres enteramente renovados. 
Es complejo resumir el impacto directo de cada uno de los aspectos que se configuraron en estos siglos. Son numerosos los avances que las actividades de los judíos en el medioevo originaron. Desde apariencias enteramente dogmáticas hasta ciertas prácticas culturales vigentes. Hay que dejar en claro que el trabajo actual es tan sólo un esbozo de los elementos principales y más importantes para las comunidades judías de los países del mundo y para la conformación social del Estado de Israel bajo su demografía mayoritariamente judía. De igual manera, es destacable el hecho de que las innumerables aportaciones medievales a la religión judaica y a su identidad fueron el resultado de la convivencia — no necesariamente armoniosa - con el auge del poderío del cristianismo en Europa y el quid del expansionismo militar del Islam. El judaísmo se caracterizó por ser la minoría de mayor relación histórica y religiosa con ambas potencias. Esto implicó una reacción de fricciones que desencadenó en ataques. Evidentemente, por ser minoría, los judíos llegaron a sufrir grandes pérdidas que dotarían a su propia historia de una apariencia desoladora y melancólica, y que, no obstante, encontraría una trascendencia sin parangón en dichas aportaciones que inclusive llegaron a influenciar a grandes pensadores cristianos y, en menor medida, a musulmanes de la misma época y de edades posteriores.

A lo largo del trabajo, hablaremos de personajes importantes en la constitución teórica de la manifestación religiosa del judaísmo en el Medioevo, como lo son Maimónides, Menahem ben Saruq, Saadia Gaon e Ibn Paquda, entre otros.

Por último, es destacable que las demarcaciones geográficas que se analizarán en el presente texto quedan, como lo mencionamos en parágrafos previos, en los límites de Europa. No obstante, habrá ciertas referencias a personajes nacidos en lo que hoy identificamos como Asia o África, pero se mantiene dentro de los parámetros temporales de la Baja Edad Media. Dichos autores son imprescindibles al momento de indicar la influencia en el presente de las aportaciones medievales judaicas. 


\section{Contexto}

De acuerdo con el teólogo católico Hans Küng (1993), en uno de sus últimos proyectos donde analiza la situación religiosa de la actualidad, en su obra El Judaísmo, afirma que la historia del pueblo de Israel se puede dividir bajo paradigmas, quien a su vez continúa la categorización que propone Thomas S. Kuhn. Küng estructura cada estadio de la religión en relación con ciertas características que definieron su desarrollo en determinadas circunstancias espaciales y, naturalmente, temporales. Es decir, se englobarán las condiciones sociales, religiosas y teológicas dentro de un macromodelo circunstancial. El «proto-judaísmo», así como los eventos consiguientes descritos en el Tanakh (Torá: ley, Nevi'im: profetas, Ketuvim: escritos) pertenecen al paradigma de las tribus de la época pre estatal, esto es, el momento que dio inicio al judaísmo desde sus etapas primitivas. Más tarde se presenta el paradigma del reino de la era monárquica, donde las principales figuras son David y Salomón, dentro de un contexto político de divisionismo por la separación del reino del norte con el del sur. El exilio en Babilonia durante el año 586 a.C. hasta el 538 a. C. dará pie al paradigma de la teocracia del judaísmo post exílico, en el que la personalidad del judaísmo se encontrará severamente criticada por personajes como Nehemías y Esdras, entre otros. Llegado a este punto, el judaísmo habrá transitado por los elementos fundamentales dentro de su propia historia en la que su configuración como religión estará fuertemente afianzada. Ahora los judíos del mundo conocido se reconocen como tal.

Tras la destrucción del Templo en el año 70 AD, y de Jerusalén en el año 135 AD, la homogeneidad en las prácticas religiosas y en el reconocimiento de una identidad firme darán la bienvenida a un nuevo estadio: el paradigma rabínico-sinagogal de la Edad Media. Será el momento en el que el judío asimile una religión que se enfrenta a los nuevos retos de un mundo enteramente distinto a aquél demarcado en el Levante Mediterráneo, en el cual coexistió prácticamente desde sus inicios. Si bien, sabemos que los judíos ya habían comenzado a movilizarse en la Antigüedad a otras partes fuera de los reinos de Israel y Judá, no podemos afirmar que hayan concebido una identidad como los judíos que ahora migraban. Estos judíos, los del paradigma medieval, tendrán por elementos fundamentales al rabino y a la sinagoga, símbolos de una fe edificada en las escrituras y en una tradición 
que permitirán la vida en una diáspora como lo que son: herederos de una fe monoteísta que rompió con otros paradigmas de las culturas históricas en la Antigüedad y que siempre llevaría consigo la responsabilidad de la memoria de una cultura privilegiada por la divinidad.

La materialización del paradigma del que habla Küng (1993) alcanzará su punto álgido con la unión ideológica de los pueblos judíos que viven en Diáspora, y aquello que propiciará el desarrollo de las comunidades cuasi uniforme en términos súper estructurales será la recopilación definitiva de los textos que conformarán la Torá Oral y de los comentarios de eruditos de la Antigüedad del Talmud. La unidad que existirá será en cuanto a su correligionario y con su religión misma. Sería durante el medioevo, en tierras musulmanes y cristianas, que los judíos vivirían un auténtico auge en los campos de la filosofía, la teología y el misticismo con trabajos que definirían el paradigma al que entraron con la finalización de las guerras judeo-romanas. ${ }^{2}$

Incluso, los judíos lograron avances en campos ajenos a su religión y se aventuraron a la aportación que cualquier élite intelectual encontraría oportunidad en facilitar. No obstante, lo que llama la atención de las aportaciones culturales, científicas, literarias y — con una osadía verdaderamente encomiable - al sector gubernamental en cuanto a los cargos dentro de sus sociedades, es que no era reconocida como una élite, sino que existía un consenso en los países de la cristiandad y en los islámicos de que los judíos eran una minoría segregada; en otras palabras, los judíos fueron el único grupo minoritario de la época medieval que logró éxitos palpables ${ }^{3}$. Así, confirmamos lo que aseveró Moisés Maimónides, el más grande pensador judío de la Edad Media, al decir que el arma más poderosa de cualquier judío es el intelecto, en conjunto con una razón fundada en sus propias enseñanzas religiosas. (Johnson, 2010).

Ahora bien, tales logros sólo podían adquirirse mediante la unión que ya se mencionaba previamente, y la cohesión se presentó a través de la ayuda mutua en comunidades,

\footnotetext{
${ }^{2}$ En este libro introductorio, se hace énfasis en el aspecto intelectual que se desarrolló dentro del judaísmo a partir de este paradigma. Cfr. Cohn-Sherbok, D. (2003). Judaism: History, Belief and Practice. New York: Routledge, p. 12

${ }^{3}$ Küng recalca el intelectualismo. Cfr. Hans Küng, Op. Cit. p.162
} 
especialmente en los guetos característicos de la Edad Media. Autores como Bernhard Blumenkranz afirman que el gueto de los judíos aparece inicialmente como una forma de vivir en comunidad que fue elegida voluntariamente y que con el paso del tiempo fue tomando el rumbo de un mecanismo de segregación. Mediante el trabajo y la residencia en este tipo de comunidades, se gestaron nuevas necesidades colectivas, como las exigencias dietéticas, las distintas formas litúrgicas y, especialmente, la búsqueda de una nueva estrategia educativa. Esta forma de vida que llegó a condiciones precarias, en la que el único propósito de la autoridad fue depauperar al otro, encontró cabida en futuras manifestaciones de vida comunitaria, y bajo estos supuestos sabemos que las distintas exigencias de los grupos ortodoxos judíos en la actualidad son un vestigio del medioevo (Küng, 1993).

Paralelo a las condiciones impuestas al pueblo judío en los países cristianos, en los territorios de hegemonía islámica, la división en aljamas de las ciudades tuvo el mismo efecto en el individuo que en los guetos. Sin embargo, al expandirse significativamente en su espacio asignado, llegó a aparecer en la historia como la demarcación geográfica del medioevo que dotó de incomparables oportunidades a los judíos, esto es, el lugar de máxima expresión intelectual. Fue uno de los momentos apoteósicos de la cultura judaica que no ha podido compararse con otro, sino hasta bien llegada la modernidad con los numerosos judíos galardonados con el premio Nobel en diversas áreas y con las proezas tecnológicas — en el más general sentido de la palabra — del joven Estado de Israel (CohnSherbok, 2003).

Sabiendo esto, analizaremos los elementos más trascendentes que sobrevivieron al pasar de los siglos sin adaptarse bajo modernas formas con la llegada de nuevos paradigmas hasta llegar a la actualidad. Se profundizará en cuatro campos fundamentales en los que, indiscutiblemente, hubo mayores aportaciones tanto a la cultura como a la religión: (1) las escrituras, principalmente en las diversas exégesis elaboradas en el medioevo de los textos que sientan las bases de la misma religión; (2) la lengua, que depende en mayor medida del mismo proceso que se describía en la creación de las nuevas prácticas religiosas como un mecanismo de producción de una identidad; (3) aquellos elementos que surgen por las 
políticas antijudías que el cristianismo y el islam impusieron de manera generalizada y que, como un corolario, tuvo algunos efectos que modificarían la concepción del judío desde una visión externa y una interna; y, por último, (4) las prácticas religiosas, las cuales son producto de un proceso de sociabilización dentro de los distintos aspectos sociológicos y psicológicos que dan pie a nuevas formas de enfrentar la realidad en cualquier comunidad.

\section{Escrituras}

El Islam no se ha equivocado en designar a los judíos y a los cristianos como "la gente del libro". El rostro de las tres religiones abrahámicas con mayor número de fieles gira en torno a un texto fundacional que le dotó de primacía sobre el resto de las religiones. En una palabra, no es epatante el apego a las escrituras de las religiones monoteístas. Y, el judaísmo, por ser la raíz de esta tradición histórica, constituye la máxima expresión de ser una religión "del libro".

El lapso de tiempo que se trata en este trabajo representa la configuración de un enfoque más consciente en términos de escritura, puesto que la religión judaica pasó por una crisis de interpretación algunos siglos atrás. En Babilonia surgió una necesidad imperiosa por llegar a una renovación de las escrituras. No es que las escrituras fueran reconocidas como defectuosas, sino que era la interpretación de la corriente dominante en el judaísmo la que fue observada como imperfecta. Así, como en cualquier movimiento antagónico de la religión ordinaria, se buscará crear la oposición a las prácticas que muestran una contradicción de lo que establece el libro hegemónico. Es de esta manera como el movimiento caraíta dentro de la religión judía entró en vigor a los inicios del siglo VIII AD.

Buscó esclarecer las prácticas que encontraban poco fundamento dentro de los textos mediante un mecanismo de Sola Scriptura. La negación de ciertas tradiciones en la praxis religiosa fue el resultado de una estrategia para purificar la religión que gestaron los patriarcas al inspirarse en Dios para escribir los textos. Es decir, el movimiento condenó las interpretaciones y comentarios que se hubieran elaborado posteriormente al paradigma post exílico, que se mencionaba previamente -como un movimiento autoritario anti- 
rabínico-. Se habrían de apegar al pie de la letra en lo establecido en el Tanakh. Huelga mencionar que esta abreviatura de índole dogmática surge en la Edad Media, como una reacción evidente a toda esta crisis que ponía en peligro la unidad étnica y religiosa del judaísmo. ${ }^{4}$

¿Qué respuesta dio la corriente principal del judaísmo al observar la amenaza potencial de esta nueva escuela del pensamiento originada en el seno de su poderío en Babilonia bajo los exilarcas? Como reacción inmediata, la élite intelectual empezó a proponer nuevos caminos donde la tradición armonizara con el Tanakh. Uno de los exponentes principales del nuevo movimiento «contra-caraíta» fue Saadia Gaon. Él encabezaría la crítica intelectual en la que se desarrollaría argumentos de temas filosóficos y teológicos por vez primera en el judaísmo no practicados sino desde los tiempos de Filón de Alejandría. Saadia Gaon sería una fuente de influencia de grandes pensadores del medioevo como Maimónides y Yehuda HaLevi. (Küng, 1993)

Una aportación que daría un auxilio a la defensa del judaísmo tradicional fue el trabajo de Menahem ben Saruq, quien por primera vez en la historia de la cultura hebrea, analizó bajo métodos y enfoques técnicos las sagradas escrituras para analizar la lengua hebrea que poco a poco iba perdiendo importancia y, consecuentemente, caía en desuso. Los judíos de Europa se adaptaron a las circunstancias de su sociedad. Esto implicaba que el hebreo dejaría de usarse como lengua de la comunidad, cuestión que se analizará con mayor profundidad en el apartado de la lengua. Lo que importa, en cuanto a las Escrituras, fue que Menahem Ben Saruq estableció tecnicismos que se apropincuaban a la investigación gramatical de los textos del Tanakh. La trascendencia fue tal, que auxilió a los pensadores de los siglos posteriores a encontrar un sentido más puro, hablando en términos de lingüística, y a crear una exégesis que se apegara a lo que los autores pudieron referirse en su momento. (Maeso, 1960)

Otro de los pensadores prominentes durante la época medieval, tras la crisis del caraísimo fue Salomón Ben Isaac de Troyes, mejor conocido como Rashi, proveniente de la Francia

\footnotetext{
4 "The title that figures on modern editions is Tanakh [...]. This abbreviation has been in use since the Middle Ages". Cfr. De Lange, N. (2002). An Introduction to Judaism. Cambridge: Cambridge University Press, p.48.
} 
septentrional. Pasó a la historia por enriquecer la apología de la corriente tradicional del judaísmo con sus vastos comentarios a la Torá (Cohn-Sherbok, 2003). A partir de Rashi, los comentarios elaborados por eruditos ya no se enfocarían exclusivamente en la Torá. Es decir, lo que había era trabajos que tenían por propósito aclarar misterios dogmáticos encontrados en los primeros cinco libros de la Biblia. A partir de ese momento, habría comentarios en otros libros concernientes a los profetas y otros escritos de gran importancia para la religión (Rabinowitz, 2007). Y no sólo logró eso como un elemento substancial que se observa en la actualidad judía. Fue él quien defendió la noción de la incorporeidad de Dios, que daría pie al comentario de Moisés Maimónides como defensor central de dicha idea.

En la Edad Media, dentro de las algunas — más numerosas - comunidades judías asentadas por toda Europa se tenía un concepto de Dios como un ente antropomórfico, por las variadas alusiones en algunos textos del Tanakh en cuanto a Dios y por influencia de las hagadot (homilías) en dichas comunidades. Moisés Maimónides sería el elemento determinante dentro de la historia del judaísmo en la erradicación de tal noción sobre el Dios único. Afirmaría continuamente en sus escritos que si se llegase a leer a un Dios antropomórfico, sólo sería válida la interpretación alegórica de esas palabras. A partir de su popularidad con escritos históricos como La guía de los perplejos, se volvería una idea aceptada universalmente en el judaísmo de que Dios, bajo ninguna circunstancia, puede ser entendido como un ente con apariencia humana (Siegfried y Loewe, 1979). Así dio inicio a una época pletórica de comentarios bíblicos que tendrían efectos muy directos a la comprensión de tales textos, especialmente en términos de la preparación religiosa y teológica en todas las comunidades del mundo.

Después de la llegada de numerosos comentarios a la Torá y al Talmud, empieza a haber muchos escritos que disentirán en sus puntos de vista, por lo que habrá una nueva tendencia en el siglo XII de crear una literatura en torno a dichos escritos. Se etiquetará como un comentario hacia los escritos rabínicos de la época y surgirá un nuevo género literario dentro de la cultura hebrea. En primeras instancias, y como parte importante de la herencia del judaísmo actual es la literatura ética, que por vez primera en toda la historia de la 
religión, se da un enfoque en la expresión filosófica del comportamiento humano. El primer trabajo de este tipo es el Hovot Halevavot por Joseph Ibn Paquda. La aportación más significativa de esta obra es la reflexión sobre diez virtudes morales que todo judío ha de tomar en consideración en la actuación de la vida cotidiana. La literatura ética es la expresión de los judíos intelectuales en cuanto a su rechazo a la influencia de la filosofía aristotélica dentro de la filosofía judía. (Gelin, 1952)

Más tarde viene un nuevo género literario: la recopilación de historias en forma de libro. Las obras más importantes son: Midrash Aseret ha-Dibberet, Alfa Beta, Sefer ha-Maasiyyot y el Exempla. La característica de este nuevo género es que se recopilaron adaptaciones de narraciones bíblicas, incluyendo algunas sátiras de las mismas que surgen tras la necesidad de juntar en un canon todos los escritos que se habían ido produciendo desde el cambio de paradigma. El cual, como se ha comprobado ya, era de un número exorbitante con demasiadas aportaciones. (Alba, 1991)

No obstante, ha llegado el momento de analizar el elemento de mayor trascendencia y que, a no ser por las circunstancias de las épocas posteriores bajo la presión de la catedrocracia que se empecinó en mantener vivas las tradiciones de las escrituras, pudo haber constituido un factor para el cambio y la llegada de un nuevo paradigma, pero los siglos posteriores eliminaron tal posibilidad con el arribo de la modernidad y una visión enteramente innovadora para los judíos de la diáspora. Hablamos de la Cábala. (Küng, 1993)

La herencia medieval más grande que el judaísmo actual puede tener es la Cábala. Si bien, sabemos que la tradición oral ya mencionaba ciertos elementos místicos que aparecían en la interpretación de los textos para emplear otro enfoque muy distinto al tradicional, fue en la Edad Media donde se configuró la doctrina mística en la forma de la Cábala. La cual, a su vez, estaría repleta de aportaciones culturales, litúrgicas y de prácticas religiosas que se mantendrían como tal en la posteridad.

En la Alemania medieval surgió un movimiento místico que buscaba reinterpretar los textos bajo influencia de las prácticas mágicas que rodeaban las sociedades en dichos momentos. Ellos eran los Hassidei Ashkenaz. La Cábala llegó de manera contemporánea a esta 
exégesis místico-esotérica de las Escrituras, pero con otros enfoques que se declaraban elementos atávicos, originados desde el momento de la creación bajo una revelación del Señor a Moisés, y a otros profetas. Así, emprende un nuevo rumbo el ámbito de la escritura del judaísmo al intentar comprender el aspecto oculto de la divinidad mediante observaciones que se alejan de las reflexiones filosóficas que regían hasta llegado el siglo XII. (Küng, 1993)

Sin embargo, estrictamente hablando, la influencia indirecta para la génesis de la Cábala fue una obra anónima llamada Bahir. El texto estaba impregnado de direcciones teóricas sexualizadas, y tendencias de teosofía divina. Es decir, era un trabajo que se caracterizaba por la escasa influencia filosófica de la época, y que sin embargo, funcionó como una obra que emergió la Cábala en el siglo XIII AD. Ya en sus pasajes introductores se presenta una interpretación esotérica de un verso del libro de Job en el que lo compara alegóricamente con la brillantez de la luz. Es un texto que, aun para los estudiosos de la actualidad, contiene ciertos elementos misteriosos, pues se desconoce su autoría totalmente, así como su origen geográfico.

El primer autor de textos cabalísticos, Isaac el Ciego, desconocía por completo el Sefer haBahir. Se calificó por Scholem —uno de los máximos exponentes del estudio de la Cábala de todos los tiempos - como un texto de influencia indirecta, porque ninguno de los cabalistas arcaicos llegó a tener como fuente primordial ha dicho texto, que tenía evidentes tendencias gnósticas. No obstante, es prueba fehaciente de que se empezaban a escribir textos de esta naturaleza desde Alemania hasta la España medieval. Ahora bien, el elemento primordial de la Cábala en toda su estructura son las sefirot, entendidas como el vehículo que se establece para comprender la organización de la naturaleza divina. La obra que se empleaba - y todavía hoy se emplea - para conocer las interpretaciones cabalísticas es el Zohar. Éste es no es un libro en el sentido estricto de la palabra, sino que ha de entenderse como un cuerpo literario completo con distintos acercamientos a los textos judíos.

El movimiento cabalístico fue recibido muy calurosamente por los estudiosos de los siglos XII y XIII. El mayor impulso que recibió y, por el que muchos autores aseguran que tomó 
un camino de celebridad en la diáspora medieval, fue la aceptación y difusión de Moisés Najmánides en sus obras bajo varios puntos de vista místicos en cuanto a las Escrituras (Cohn-Sherbok, 2003). Más adelante, se comenzó a perfilar la Cábala en géneros literarios que poco tenían que ver con ella. De ahí que la poesía de Yehuda HaLevi fuera un incentivo para otros autores de implementar en sus trabajos elementos inspirados en las nuevas interpretaciones cabalísticas (Johnson, 2010). En estas múltiples manifestaciones narrativas, empezó a crecer el interés literario cabalístico hasta un grado tan elevado que surgieron tres tendencias fundamentales: la narración hagiográfica, la historia mitológica y la historia mística (Scholem, 1965). Bajo todos estos medios de popularización, hoy podemos observar la herencia de la Cábala en la vida de los judíos ultra-ortodoxos, quienes, bajo la influencia de la mística pietista (Hassidei Ashkenaz) y la mística cabalística dieron origen a sus diferentes ritos que hasta hoy se mantienen (Johnson, 2010, p.292).

Finalmente, describamos los aspectos que, por intermediación de la Cábala, se transformaron en una práctica comunitaria en la diáspora y que hoy siguen vigentes tal y como se originaron. Fueron, principalmente, tres campos: la oración, la ética y las costumbres. Los judíos en la actualidad practican lo que alguna vez se concibió en la Edad Media: las vigilias de Pentecostés, de Hoshana Rabbah y la del Séptimo Día del Pesaj. Asimismo, es medieval el hecho de que en ciertas comunidades judías, en Shabat, se cante una melodía muy célebre, el Lecha Dodi, la recitación del Cantar de Cantares o la recitación del libro de Proverbios. Se sabe que es medieval y cabalístico porque surge de la proposición oblativa de meditar el Shekhinah (Johnson, 2010, p.292).

De ahí que - más allá de la trascendencia que tiene la Cábala en el judaísmo actual, originada en la Edad Media- muchas prácticas que son producto de las Escrituras durante el medioevo tienen un impacto directo en la actualidad en aspectos verdaderamente importantes, como lo son las prácticas religiosas y la enseñanza de la misma religión a todo judío practicante que tiene por obligación instruirse en su propia fe. Ahora, se verá el impacto que ha tenido la lengua, que a pesar de que ocurrió en menor medida en comparación a la escritura, implica evidentes transformaciones en una sociedad como la conocemos actualmente. 


\section{Lengua}

La división de la historia lingüística del hebreo es compleja desde el momento en que el pueblo judío hizo lo que muchos otros pueblos tuvieron que hacer: migrar. Es de admirarse que un pueblo, después de su migración, se haya mantenido unido bajo las formas elementales de una diáspora. Y, es todavía más encomiástico el hecho de que, siglos después de empezar una vida en diáspora, lograran mantener su propia lengua hasta el punto de revivirla con la creación del Estado de Israel, con sus necesarias evoluciones lingüísticas.

El estadio de la lengua hebrea que se ha de analizar en el presente trabajo es uno de los estadios más complicados de su historia, porque, como se ha planteado ya, el pueblo judío se configuró uniformemente a pesar de vivir no como una nación o una etnia perteneciente a su propio territorio, sino como un pueblo disperso por todos los rincones del mundo conocido.

Es el Hebreo Medieval (HM) una lengua casi en peligro de extinguirse como una lengua materna. Su uso generalizado sólo encuentra espacio en la liturgia y en las oraciones, esto es, la religión es el refugio del hebreo medieval. Todavía existen algunas comunidades que lo emplean como una lengua cotidiana, pero no es la lengua hegemónica de su propia colectividad. Siguiendo esta línea de pensamiento, se llegará a la conclusión de que el yidish $^{5}$ surge en la Edad Media. Los judíos que llegaron a la Germania medieval llevaban consigo la lengua, pero las futuras generaciones lograron una suerte de sincretismo lingüístico entre el hebreo-arameo y el alemán medieval en el que surgió una nueva lengua. El yidish es de capital importancia, puesto que el "renacimiento" del hebreo al hebreo moderno tiene características asimiladas en términos de préstamos y calcos de éste. Incluso, hoy muchas comunidades judías importantes en el mundo hablan y mantienen registros en yidish. Evidentemente, las primeras generaciones hablaban una lengua que variaba de región en región dentro de los límites de la Alemania medieval, pero que, con el paso del tiempo, marcó el inicio de un vínculo entre comunidades para fortalecer la identidad judía en edades posteriores. (Küng, 1993, p.165)

\footnotetext{
${ }^{5}$ Dialecto de los judíos asquenazí.
} 
Asimismo, como se mencionaba en parágrafos anteriores, el interés por estudiar el Tanakh más a fondo implicó la investigación minuciosa dentro de la filología hebrea, tras las exigencias de los caraítas por un retorno a la religión pura y depurada del libro. Los estudiosos árabes, con su auge en Al-Ándalus representaron del mismo modo un aliciente por elucubrar en la estructura de la lengua santa. Sería un momento de concentración filológica que había perdido el interés desde tiempos que se remontan a la derrota en las guerras judeo-romanas (Sáenz-Badillos, 1988, p.202).

Dentro de este renacer técnico del hebreo, se aprecia el último estadio de la lengua en cuanto al embellecimiento de la caligrafía hebraica. Las comunidades sefarditas, que convivían con los musulmanes en gran medida, presentaron un ávido interés por la belleza caligráfica de su propia escritura, cabe mencionar aquí un juicio de valor donde probablemente esta necesidad por dotar de una estética manual a la propia escritura haya ocurrido por el arte islámico que prestó una radical importancia a su propia caligrafía. En la modernidad, ya no se interesarían por embellecer la caligrafía, mucho tiene que ver la llegada de la imprenta. Sin embargo, la tipografía de caracteres hebreos de la imprenta y de la actualidad se basan en la caligrafía medieval, por ser el momento último de escribir manualmente las letras del hebreo. Pero, así como la coexistencia con las otras religiones abrahámicas hizo brotar éxitos que perdurarían, así también crearon sentimientos de pusilanimidad que se mantendrían para la posteridad.

\section{Antijudaísmo}

La división en aljamas en Al-Ándalus, la creación primitiva de guetos en algunos reinos cristianos, así como la segregación total en poblados alejados del eje de concentración en los mismos reinos de la cristiandad provocaron un sentimiento de hostilidad universalizada en contra de los judíos. Ya se ha mencionado previamente que los judíos representaban la única minoría exitosa de toda la Edad Media europea. Ello ha propiciado el sentimiento de animadversión en las esferas hegemónicas. 
Hubo tiempos de relativa paz en ciertos momentos de la Alta Edad Media dentro de las comunidades judías, sin embargo, llegada ya la Baja Edad Media un conjunto de hostilidades llevadas al extremo dieron la apertura a medidas como la expulsión de sus propios poblados y de sus viviendas. Especialmente tras la llegada de las cruzadas a partir del siglo XII. A pesar de que el papa Urbano II nunca hizo alusión a atacar a los judíos al promulgar la primer cruzada en 1096, los soldados y, después de presenciar sus acciones, los pobladores asumieron que era su responsabilidad odiar a los judíos ${ }^{6}$. No sería sino hasta una centuria más adelante cuando el papa Inocencio III, en el histórico Concilio Lateranense IV, promulgara edictos abiertamente en contra de los judíos al establecer que habrían de vestirse de manera distinta a los cristianos para poder ser reconocidos públicamente.

También les prohibieron salir de sus hogares en Semana Santa por todos los escándalos de la difamación de la hostia y de la sangre (Cohn-Sherbok, 2003, p.135). Sin dar ningún respiro, empiezan los mecanismos en Francia y Alemania de expulsar a los judíos de sus tierras, así como numerosas masacres que marcarían la historia desoladora del judío medieval y quedaría plasmado en sus rezos para nunca olvidar las injusticias (p.160). Así, entre los años 1348 y 1350 se efectuó una de las masacres más violentas a los judíos, donde 300 comunidades fueron aniquiladas en Alsacia, Renania, Turingia, Baviera y en Austria. Se afirmaba que los 30 judíos habían envenenado los pozos para crear la Muerte Negra (Küng, 1993, p.170). Una elevada cantidad de mitos surgieron por parte de los gentiles alrededor de la figura del judío que, al ser herencia del medioevo, aún hoy podemos notar en el prejuicio del gentil. Un ejemplo es el mito medieval que narraba a un judío llamado Ahasver, quien habría formado parte de la muchedumbre que añoraba la crucifixión de Jesús de Nazaret y que, durante el camino hacia el Gólgota se habría mofado de él. Por este - claramente inventado - vilipendio sería condenado a errar por una eternidad. Aún hoy podemos ver cómo en numerosas representaciones de la Vía Crucis se dramatiza al personaje del judío errante en las tradiciones de la remembranza en la Semana Santa. Inclusive, hubo comunidades medievales que se atrevieron a generalizar la condena del

\footnotetext{
${ }^{6}$ Cfr. Chazan, R. "The Anti-jewish violence of 1096: Perpetrators and Dynamics". En Anna Sapir Abulafia (Ed). (2002). Religious Violence between Christians and Jews: Medieval Roots, Modern Perspectives. Hampshire: Palgrave, p.35.
} 
judío errante a los judíos en su totalidad, como un pueblo que habría de errar por el resto de la historia hasta el momento de la segunda venida del Cristo, cuando se castigara eternamente al pueblo díscolo. (Küng, 1993)

Al calificar a los judíos como el pueblo difamador y, peor aún, de ser "deicida", el odio en contra suyo generó una violencia sin poder equipararse. Se llegaron a celebrar disputas entre las autoridades cristianas contra las judías en donde el propósito era desprestigiar la imagen de la religión judía ante los ojos de la religión verdadera, del "nuevo pueblo de Israel", que, como corolario, finalizaban con el triunfo de la argumentación cristiana y la quema del Talmud. Un ejemplo ocurrió en Barcelona, con Najmánides, en 1263, en la que los textos de ambos lados parecen reclamar la victoria. (Küng, 1993)

Por supuesto, el pueblo judío no recibiría los ataques sin responder, pero adverando las palabras de Moisés Maimónides de que el arma del judío es la intelectualidad, la respuesta sería astuta y, en cierta medida quizá discreta. Se creó una literatura denominada Toledot Yeshu en la que el propósito era mofarse de la figura de Jesús de Nazaret, así como de los cristianos en su totalidad. Una de las obras más célebres fue El oprobio de los santos, por Isaac ben Moses. (Küng, 1993, p.167)

Pero la violencia fue tan grave a los ojos de los judíos que hubo una reacción psicológica, justificada en apotegmas ideológicos al pensar en una vuelta al mesianismo y a la apocalíptica. Los versículos de los profetas, así como de algunos salmos hablaban del martirio de los justos. Llevaban tonos soteriológicos tales argumentos observando la realidad social que les rodeaba. Por ello, empieza una sofisticación en los procesos de excomunión y anatemización para aquellos judíos que se convertían y negaban su propia fe para salvarse del yugo de la Inquisición o de los castigos impuestos por los reinos cristianos. Así, las ceremonias y los protocolos que han de seguirse en el proceso de excomunión de los judíos, llamadas Cherem, tienen sus raíces en las masacres de la Edad Media. (Johnson, 2010, p.290)

Así se ratifica cómo también la idiosincrasia en la historia puede generar prácticas en la actualidad. También el antijudaísmo sirvió implícitamente a las comunidades judías para 
nunca dejar en el olvido el maltrato que se ha recibido a lo largo de su historia, y que, sabemos, les ha servido como un motor para salir adelante. De manera indirecta, también, se encuentra el efecto en la visión del judío. Puesto que los aspectos negativos, fruto del prejuicio de las sociedades históricas, han dado pie a una tipificación poco fundada. Eso también es herencia de la Edad Media que ha recaído sobre el judaísmo directamente.

Ahora, se desarrollarán las prácticas religiosas de los judíos en la actualidad que encuentran su origen en el medioevo. Son justamente los indicios más directos que se han rastreado hasta la actualidad.

\section{Prácticas religiosas}

Moisés Maimónides proporcionó al judaísmo trabajos intelectuales que modificarían ciertos dogmas. Sucedió así por el apego a las escrituras en sus ideas y conceptos. Así como la doctrina de la incorporeidad de Dios es ahora universalmente aceptada, también en el campo de la práctica religiosa hubo aportaciones por parte de este personaje. La más importante es la Confesión de fe que elaboró y que, por su calidad intelectual y dogmática, se transformó en un auténtico símbolo de fe en el que el judío de la actualidad tiene que rezar en los devocionarios a la hora de finalizar la oración matutina. Abarca trece puntos esenciales que todo judío reconoce como su credo.

“1) Creo con plena convicción que el Creador hizo y guía a todas sus criaturas y que él solo realizó, realiza y realizará todas las obras. 2) Creo con plena convicción que el Creador es único, que ninguna unidad es igual a la suya en aspecto alguno, y que él solo fue, es y será nuestro creador. 3) Creo con plena convicción que el Creador no es un cuerpo, que lo corporal no es inherente a él, y que no tiene igual. 4) Creo con plena convicción que el Creador es el primero y será el último. 5) Creo con plena convicción que sólo el Creador merece adoración, y que no se debe adorar a otro ser fuera de él. 6) Creo con plena convicción que todas las palabras de los profetas son verdaderas. 7) Creo 
con plena convicción que el profetismo de nuestro maestro Moisés es verdadero, y que él es el maestro de todos los profetas que existieron antes de él y de cuantos le sucedieron. 8) Creo con plena convicción que la Torá, tal como la poseemos ahora, fue dada a nuestro maestro Moisés. 9) Creo con plena convicción que esta Torá nunca fue cambiada y que ninguna otra saldrá del Creador. 10) Creo con plena convicción que el Creador conoce todas las acciones de los hombres y todos sus pensamientos, pues se dice: "Él, que formó todos los corazones de todos ellos, entiende también sus acciones". 11) Creo con plena convicción que el Creador hace el bien a los que observan sus mandamientos, y castiga a los que los transgreden. 12) Creo con plena convicción en la aparición del Mesías y, aunque él se demora, aguardo diariamente su llegada. 13) Creo con plena convicción que tendrá lugar la resurrección de los muertos cuando le plazca al Creador. Alabado sea su Nombre y loado su recuerdo por siempre jamás”. (Küng, 1993, p.167)

Los judíos medievales tendrían una misma declaración de fe en sus oraciones, pero también se daría, por primera vez en la historia, un consenso universal en el judaísmo de rezar en hebreo dentro de la sinagoga. Previo a esta práctica homogénea, aún existían sinagogas que rezaban en su idioma local. A partir de la Edad Media, los judíos del mundo rezarían todas las oraciones dentro de la sinagoga en la lengua de sus ancestros.

De igual forma, ahora se les exigiría a todos los pretendientes a ocupar el puesto de rabinos una preparación académica muy estricta, pues previo a la Edad Media, un rabino era el estudioso que se llevaba el título. Aquí se nota el sentido catedrocrático del medioevo en que los elementos más importantes son la sinagoga y los rabinos.

Bajo estas condiciones religiosas, surge un número importante de ritos que, a pesar de que estaban ya dictados en la Torá, se llevarían a cabo de forma sofisticada siguiendo un protocolo riguroso. En este contexto surge la ceremonia de celebración de la preparación de 
un judío, esto es, el Bar Mitzvá, bajo las autoridades Ashkenazím de la Alemania medieval. La Torá establecía ya la edad en que el judío habría de iniciarse en su religión, pero los judíos medievales de estas regiones vieron la necesidad de festejar la ocasión y así surge la ceremonia y la festividad como un proceso a seguir. También los teólogos judíos, al observar la sofisticación de los ritos religiosos, propusieron elaborar artículos de fe que entraran en el campo del dogmatismo, en los que los judíos tendrían que repetirlos en la oración para darle importancia a su creencia consolidada y a su fe. (Moore, 1946, p.236)

También, en cuanto al tema de los ritos, el erudito medieval, Jacob ha-Gozer, que trabajó en conjunto con su hijo para elaborar el tratado Kelalei ha-Milah, en el siglo XIII, hace una guía con instrucciones concisas para la circuncisión de los varones. En este tratado se indica la exigencia de nombrar al niño durante el rito judío por antonomasia. Esto se mencionaba ya en la Torá, pero sería a partir de dicho momento en que se comenzara a efectuar como una práctica religiosa (Schauss, 1950, p.51).

Como ya se ha explicado en el surgimiento de los Hassidei Ashkenaz, la oración se volvió una parte fundamental que demostraba y reflejaba el aspecto místico de la nueva espiritualidad de la región alemana. La oración era vista y era descrita por los mismos miembros de la nueva corriente como la escalera de Jacob que se extendía desde la tierra hasta llegar a los cielos. Conociendo esta nueva perspectiva, se compuso durante el siglo XIII el Himno de la Gloria, el cual, en la actualidad, se encuentra dentro de las recitaciones centrales en las liturgias askenazíes. Las composiciones suponían un refugio psicológico ante todas las masacres y las acciones violentas en contra suya en la Alemania medieval. (Cohn-Sherbok, 2003, p.202)

Con la expansión del pensamiento cabalista por todas las comunidades judías, nuevos ritos surgieron también, pues la mística — como con los pietistas-implicaban nuevas formas de vivir la experiencia religiosa por medio de la práctica y no tanto con la reflexión, como la filosofia. De esta forma, el concepto de rasurarse la barba significaba una ruptura con la tradición espiritual. Hay que tomar en cuenta que el cuerpo era una parte fundamental donde los sefirot jugaban un rol de impacto directo. Los jasídicos, como el grupo más influenciado por el pensamiento cabalista, tomarían al pie de la letra estas indicaciones y 
quien se rasurara era considerado como un desertor ante las instrucciones tradicionales de la religión judaica. (Yeivin, 2007, p.237)

Fue también durante la Edad Media cuando surge la figura del candelabro de Hanukkah, con los ocho brazos para encender las velas (Hooke, 1958, p.149). La festividad de Rosh Hashana, a partir de este momento se celebraría por dos días, en contraposición a la celebración de una sola jornada (Moore, 1946, p.45). El ambiente de festividad era una parte necesaria dentro de las comunidades de la diáspora, puesto que también este era un mecanismo de refugio psicológico. Así surge el jolgorio que se hace en honor al novio y a la novia en su fiesta de bodas. Existía la figura del Marshalek que era una suerte de comediante que se dedicaba a letificar con festivas albórbolas en este tipo de celebraciones. (Molho, 1960, pp. 179-180)

Por último, una de las instituciones que se originó en el medioevo y que sigue jugando un papel importante en la actualidad es la del cementerio. Los cementerios judíos son construidos con un muro para alejarlo de las otras edificaciones y para representar el elevado respeto que se les tiene a los difuntos. Las costumbres sefarditas y askenazíes difieren bastante: las tumbas de la tradición askenazí constan de una lápida erigida verticalmente, mientras que la lápida sefardita está recostada o colocada horizontalmente. Ocasionalmente hay una tumba con la inscripción genizah, que es donde se colocan los libros sagrados descartados por la sociedad. A diferencia de las prácticas occidentales, no se colocan flores, sino que el judío colocará una piedra para indicar que estuvo ahí. (De Lange, 2002)

\section{Conclusiones}

Este trabajo de investigación no es más que una recopilación de los elementos más importantes originados en el medioevo que las comunidades judías del mundo mantienen hoy como si se tratara de una tradición establecida desde los tiempos inmemoriales. El esbozo que aquí se ha presentado refleja la vigencia del medioevo, pues es una etapa del judaísmo que no se coloca en el puesto de importancia que verdaderamente tiene. De igual 
forma, se comprueba el hecho de que, por muy antigua que pueda ser una religión, siempre va a tener elementos de todos sus estadios históricos, sin importar la región en los que se hayan creado tales elementos. Si bien, la religión judía ha pasado por momentos terriblemente difíciles durante su historia, la genealogía de sus componentes culturales y religiosos pueden rastrearse hasta épocas y zonas geográficas que a simple vista uno ignoraría.

Esta recopilación de datos queda en los límites de la colección de información, puesto que pueden existir más trabajos investigativos que hayan profundizado en ciertos elementos, pero resultaría interesante que la recopilación entrara en los campos de una investigación más a fondo y explicar el porqué del origen de dichas prácticas. En este trabajo sólo se ha expuesto la importancia de la era medieval y la vigencia de elementos medievales en la actualidad, pero es necesario realizar nuevos estudios que expliquen cómo surgieron dichas prácticas y rastrear el origen factual de tal o cual práctica. Sin duda, la Cábala es la herencia más importante que hoy tenemos de las épocas medievales puesto que no únicamente hay enfoques judíos en la actualidad, sino que existen ciertas disciplinas que intentan descubrir las proposiciones de esta interpretación mística.

Sin embargo, los eventos del medioevo también sirvieron para permanecer en el subconsciente colectivo de la religión judaica y del cristianismo para tomar ciertas actitudes que se quedan en los límites del prejuicio. Por un lado, los judíos tienen por mandato implícito nunca olvidar el maltrato sufrido y todas las muertes provocadas por la interpretación errónea de su existencia como religión y, por otro lado, el cristiano mantiene aún cierta actitud de desapego por el prejuicio del judío.

Por tanto, la Edad Media tiene unos efectos vivos en la idiosincrasia del judío y en sus prácticas religiosas, fruto de una herencia tradicional y también de las costumbres que quedan de generación en generación. La religión evoluciona con el paso del tiempo, tiene elementos que se adaptan a las circunstancias históricas y tiene otros elementos que se mantienen por tener características permanentes que armonizan con las nuevas circunstancias. $\mathrm{Y}$ es de esta forma como una identidad se conforma en el campo de la religión que es necesario tener para comprender el mundo actual. 


\section{Bibliografía}

Abulafia, A. (Ed). (2002). Religious Violence between Christians and Jews: Medieval Roots, Modern Perspectives. Hampshire: Palgrave.

Alba, A. (1991). Cuentos de los rabinos. Córdoba: El Almendro.

Cohn-Sherbok, D. (2003). Judaism: History, Belief and Practice. New York: Routledge.

De Lange, N. (2002). An Introduction to Judaism. Cambridge: Cambridge University Press.

Gelin, A. (1952). Morale et L'Ancient Testament.

Hooke, S. (1958). Myth, Ritual and Kingship. Virginia: Clarendon Press.

Johnson, P. (2010). A history of the jews. España: Zeta.

Küng, H. (1993). Das judentum, München. Zurich: Piper.

Maeso, D. (1960). Manual de historia de la literatura hebrea. Madrid: Gredos.

Molho, M. (1960). Literatura sefardita de Oriente. Madrid/Barcelona: C.S.I.C.

Moore, G. (1946). Judaism. Pennsylvania: University of Pennsylvania Press.

Rabinowitz, L. (2007). "Bible”. En Fred Skolink, Encyclopaedia Judaica, Vol. 3 "Ba- Blo", Macmillan Reference USA/Keter Publishing House, USA/Israel.

Sáenz-Badillos, A. (1988). Historia de la lengua hebrea. Barcelona: AUSA.

Schauss, H. (1950). The Lifetime of a Jew throughout the ages of Jewish History. New York: Union of American Hebrew Congregations.

Schaya, L. (1958). L'homme et l'absolu selon la Kabbale. France: Dervy.

Scholem, G. (1965). On the Kabbalah and its Symbolism. USA: Schocken Books.

Siegfried, S. y Loewe, R. (Eds.). (1979). Studies in Jewish Religious and Intellectual History. USA: The University of Alabama Press. 
Yeivin, Z. (2007). "Beard and shaving”. En Fred Skolink, Encyclopaedia Judaica, Vol. 03, “Ba- Blo", Macmillan Reference USA/Keter Publishing House, USA/Israel. 